\title{
Rebreathing into a bag increases human retinal macular blood velocity
}

\author{
Seiyo Harino, Juan E Grunwald, Benno J Petrig, Charles E Riva
}

\begin{abstract}
Aims-The effect of rebreathing into a bag (RB) on retinal macular blood velocity was evaluated in healthy volunteers.

Methods-Ten normal volunteers, whose ages ranged from 17 to 34 years, performed RB over 135 to 260 seconds (mean (SD) 193 (38) seconds) while retinal macular blood velocity was determined non-invasively using the blue field simulation technique.

Results-Leucocyte velocity significantly increased $(p<0.05)$ at 2 minutes and at the end of RB by $53 \%(42 \%)$ and $92 \%(65 \%)$, respectively $(95 \%$ confidence interval of the mean (CIM)). All subjects observed an increase in the density of leucocytes. At the end of RB, mean systolic brachial arterial pressure and heart rate were significantly increased by $24 \%(11 \%)$ and $37 \%(15 \%)$ respectively $(p<0.01)$. At 2 minutes, end tidal oxygen concentration in the exhaled air was $47 \%(8 \%)(95 \%$ CIM) below and carbon dioxide was $41 \%$ $(16 \%)$ above baseline $(p<0 \cdot 001)$. The RB produces a large increase in macular leucocyte velocity, suggesting an increase in blood flow.
\end{abstract}

Conclusion-Although RB has some systemic risk due to hypoxia and hypercapnia, RB for a short period of 1 or 2 minutes might be of help in the treatment of retinal arterial obstructive diseases in young patients without cardiovascular disorders if other treatments do not show any beneficial effects.

(Br f Ophthalmol 1995; 79: 380-383)

Retinal arterial occlusion (RAO) or ophthalmic artery obstructive disease usually results in
Hospital, Department of Ophthalmology, S Harino

Scheie Eye Institute J E Grunwald

B J Petrig

C E Riva

Correspondence to Seiyo Harino, MD, Yodogawa Christian Hospital, Department of Ophthalmology, 2-9-26 Awaji Higashi-Yodogawa-ku, Osaka 533, Japan.

Accepted for publication 5 December 1994 severe visual loss and treatment is seldom beneficial. A procedure that would induce a dilatation of retinal vessels and an increase in retinal blood flow could perhaps move a fresh embolism downstream into a smaller arteriole and thus decrease the extent of the ischaemic lesion. Reports in the literature have shown evidence that emboli can move downstream into smaller vessels or can completely disappear in the course of RAO. ${ }^{12}$

The simple task of rebreathing into a bag (RB) produces both hypercapnia, which is known to increase retinal blood flow, ${ }^{34}$ and hypoxia, which causes vasodilatation. ${ }^{5}$ In addition, both hypercapnia and hypoxia can also increase cardiac output and raise systemic arterial blood pressure, ${ }^{6}$ which, in turn, increase ocular perfusion pressure.

The RB procedure has been applied to treat hyperventilation syndrome. ${ }^{7-9}$ The efficacy of this method for the treatment of RAO or amaurosis fugax, ${ }^{10}$ however, has not yet been demonstrated in animal or clinical studies. ${ }^{11}$ As a first step, the aim of this study was to evaluate, non-invasively, the effect of $R B$ on retinal macular blood velocity in healthy volunteers using the blue field simulation technique.

\section{Materials and methods}

Ten healthy non-smoking volunteers (10 eyes) with a normal ophthalmic examination, except for mild refractive error, participated in this study. Their ages ranged from 17 to 34 (mean 25.8 (SD 6.3) years). All were naive with regard to retinal and respiratory physiology as well as the blue field simulation technique (BFS) ${ }^{12}$ and rebreathing procedure. Subjects refrained from caffeine consumption for at least 5 hours before the experiment since caffeine has some effect on the human macular circulation. ${ }^{13}$ This research followed the tenets of the declaration of Helsinki. Informed consent was obtained after the nature, possible consequences, and risks of this study were fully explained.

Retinal macular blood velocity was measured using the BFS technique, ${ }^{12}$ which allows the determination of leucocyte velocity (Vleuco) in the macular capillaries. In this technique, subjects can adjust the velocity and density of simulated leucocytes displayed on a computer monitor to match those of their own entoptically observed leucocytes.

In the macular microcirculation, where capillaries are $7-10 \mu \mathrm{m}$ in diameter, the Vleuco is equal (within a few per cent) to the mean velocity of whole blood. ${ }^{14}$ This velocity can be assumed to represent flow because 

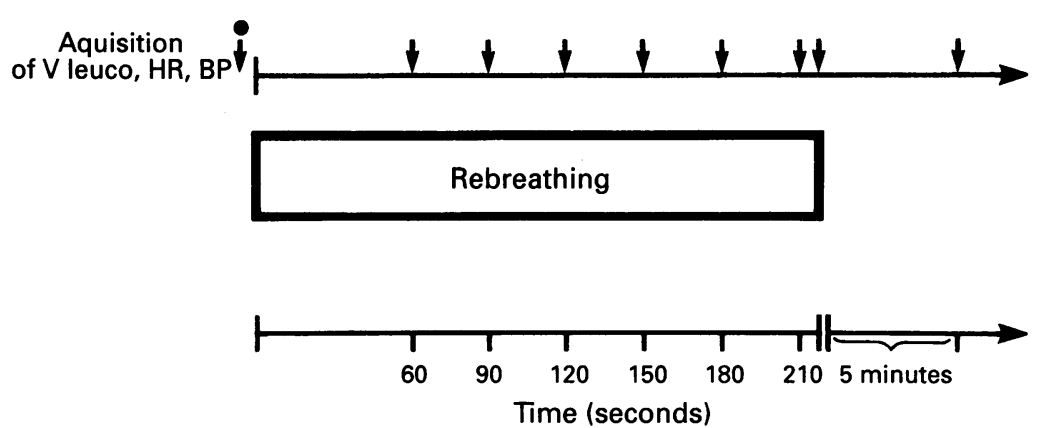

Figure 2 Time sequence of measurements of heart rate (HR), systemic blood pressure $(B P)$, and macular leucocyte velocity (Vleuco) during rebreathing $(R B) .(\bullet)=$ Baseline.

these capillaries probably have a constant diameter. ${ }^{15-17}$

\section{EXPERIMENTAL PROCEDURE}

For RB, a closed system with a 5 litre reservoir bag was used (Fig 1). The total volume in this system was $5660 \mathrm{ml}$. End tidal carbon dioxide and oxygen levels in exhaled air were measured continuously using a carbon dioxide monitor (Datex 223) and oxygen monitor (ColePalmer 095506). During the experiment, the brachial arterial pressure was measured at 30 second intervals with a standard digital sphygmomanometer cuff. The heart rate was monitored continuously by an earlobe transducer. Breathing rate was determined from end tidal carbon dioxide tension in the exhaled air.

The blue field entoptic phenomenon and the computer simulation were viewed alternately with the dominant eye. Firstly, subjects practised five matching trials comparing two simulated fields. Then, a practice session of 10
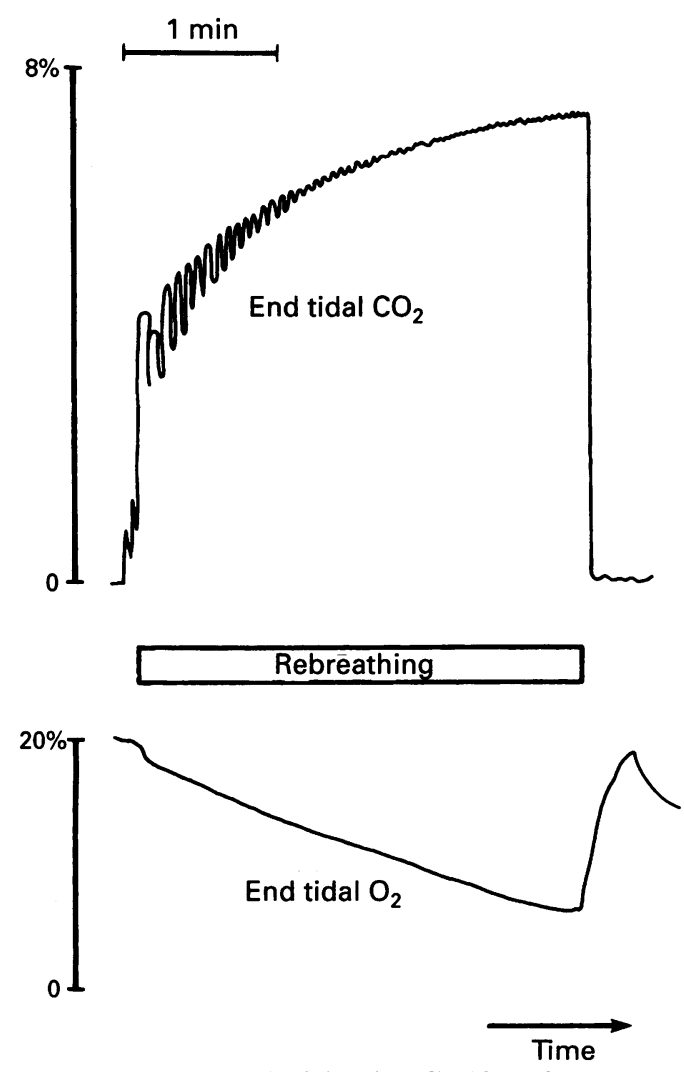

Figure 3 Typical end tidal carbon dioxide and oxygen responses during rebreathing. matching trials comparing the blue field entopic phenomenon to the computer simulation was conducted in each subject. The coefficient of intrasubject Vleuco variability was mean $19.0 \%$ (SD $7 \cdot 5 \%$ ) (range $9-31 \%$ ) for these trials.

A practice session of $\mathrm{RB}$ was also performed to familiarise subjects with the actual experimental procedure of rebreathing. Volunteers were asked to maintain $\mathrm{RB}$ for as long as possible. Baseline measurements of leucocyte velocity as well as density and pulsatility were obtained by one matching trial before actual RB. To facilitate the measurement procedure during $R B$, only the velocity of the simulated particles was adjusted while density and pulsatility of leucocytes were kept constant at baseline values. Data were acquired every 30 seconds starting at 1 minute after the beginning of $R B$, at the end of $R B$, and at 5 minutes after the end of RB (Fig 2).

Percentage increases in Vleuco at 2 minutes of $R B$ and at the end of $R B$ were calculated and averaged. Statistical analysis (paired $t$ test) was performed with the results obtained at baseline, at 2 minutes of $R B$, and at the end of $R B$.

\section{Results}

Typical end tidal carbon dioxide and oxygen concentrations during $\mathrm{RB}$ are shown in Figure 3. RB was performed for 135 to 260 seconds (mean 193 (SD 38) seconds). During $\mathrm{RB}$, subjects experienced some suffocation and tiredness. Two of them had a light headache for a few hours. There were no serious complications.

For each subject, the Vleuco over the course of $\mathrm{RB}$ is plotted in Figure 4. Percentage change in Vleuco, systemic blood pressure, heart rate, and end tidal carbon dioxide and oxygen concentration are summarised in Table 1 . The Vleuco increased significantly above baseline at 2 minutes and at the end of $\mathrm{RB}$ by $53 \%(42 \%)$ and $92 \%(65 \%)(95 \%$ CIM), respectively. These increases were statistically significant ( $p=0.018$ and 0.019 , respectively). Nine out of 10 subjects observed an increase in Vleuco during RB; only one subject who had a very high velocity at baseline showed a decrease in Vleuco. All subjects reported a subjective increase in the density of leucocytes within the field of observation after approximately 1 minute of RB. This increase was not measured quantitatively during the experiment. Following the end of RB, Vleuco returned towards baseline and at 5 minutes Vleuco was higher by $15 \%$ (24\%) (95\% CIM, $\mathrm{n}=9$ ). This difference from baseline, however, was not statistically significant.

There was no significant correlation between the percentage changes in Vleuco and the end tidal carbon dioxide or oxygen levels both at 2 minutes and at the end point. Moreover, no significant correlation was found between Vleuco and the duration of RB.

\section{Discussion}

Nine out of 10 volunteers demonstrated an 


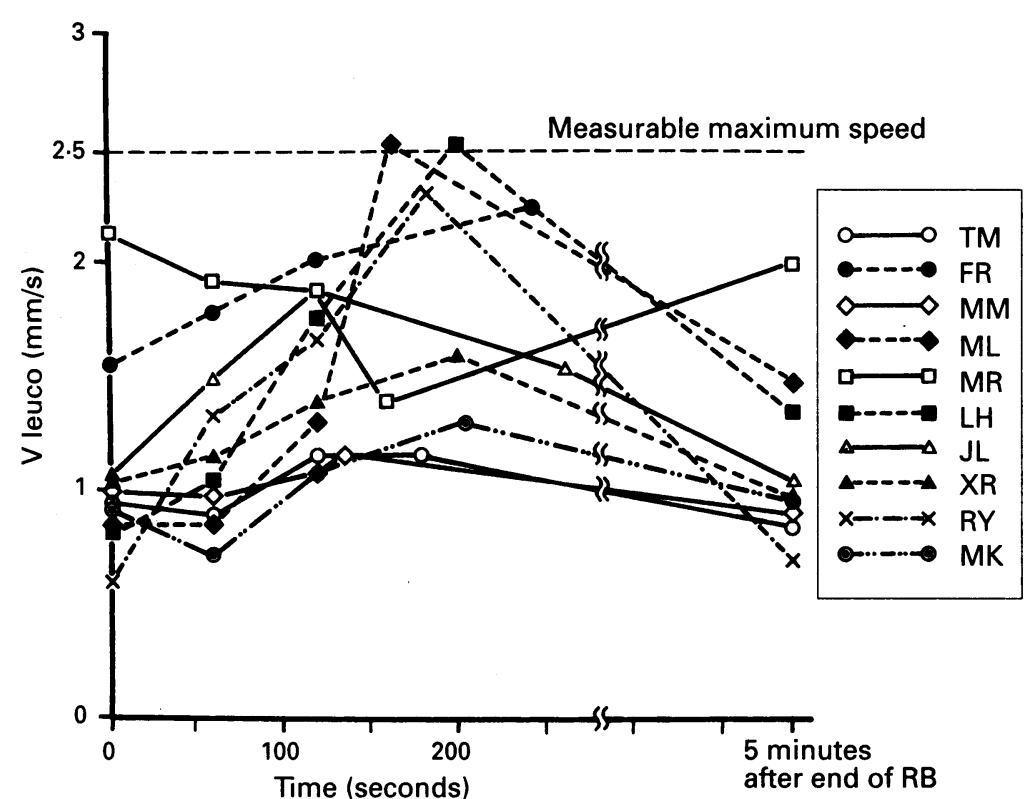

Figure 4 Macular leucocyte velocity, Vleuco at 2 minutes, end of rebreathing $(R B)$, and 5 minutes after the end of $R B$ for each of the 10 subjects.

increase in Vleuco. For the group, there was a significant average increase of $53 \%$ at 2 minutes and an even larger average increase of $92 \%$ at the end of RB.

The rather small variability in end tidal oxygen concentration at the end of $R B$ suggests that a decrease in end tidal oxygen of approximately $64 \%(4 \%)(95 \%$ CIM) is the factor that forces a subject to terminate the experiment. This is confirmed by previous studies showing that during breath holding attempts the drop in partial pressure of oxygen in terminating the procedure is more important than the rise in partial pressure of carbon dioxide. ${ }^{18}$

The large variability in the increase in Vleuco cannot be explained by the variability of the systemic response, ${ }^{14}$ as measured by the end tidal carbon dioxide and oxygen concentration, since there were no significant correlations between Vleuco and those variables. Tsacopoulos ${ }^{3}$ showed that mean retinal circulation time, measured by fluorescein angiogram and densitometry, decreased significantly with increases in arterial partial pressure of carbon dioxide. Therefore, the variability in the response in Vleuco could be due to the variability of arterial carbon dioxide among individuals.

Many studies have been performed to investigate the change in retinal haemodynamics under the conditions of either hypoxia, hypercapnia, or both. ${ }^{319-22}$ Using BFS and measurement of retinal vessel diameter, Fallon et al ${ }^{19}$ reported a $36 \%$ increase in macular blood flow at 10 to 12 minutes of isocapnic hypoxia $(10.5 \%$ oxygen

Table 1 Percentage change (SD) in leucocyte velocity in the macular capillaries (Vleuco), systemic blood pressure (BP), heart rate ( $\mathrm{HR})$, and end tidal $\mathrm{O}_{2}$ and $\mathrm{CO}_{2}$ concentration

\begin{tabular}{llllll}
\hline & Vleuco & $B P$ & $H R$ & $\mathrm{O}_{2}$ & $\mathrm{CO}_{2}$ \\
\hline 2 Minutes of RB & $53(42)^{\star}$ & $17(12)^{\star \star}$ & $23(18)^{\star \star}$ & $46 \cdot 6(10 \cdot 5)^{\star \star \star}$ & $38 \cdot 6(19 \cdot 2)^{\star \star \star}$ \\
End of RB & $92(65)^{\star}$ & $26(13)^{\star \star}$ & $37(20)^{\star \star}$ & $63 \cdot 6(6 \cdot 1)^{\star \star \star}$ & $51 \cdot 2(26 \cdot 0)^{\star \star \star}$
\end{tabular}

Numbers are expressed as $95 \%$ confidence interval of the mean.

$\mathrm{RB}=$ rebreathing procedure

${ }^{\star} \mathbf{p}<0.05 ;{ }^{\star \star} \mathbf{p}<0.01 ;{ }^{\star \star \star} \mathbf{p}<0.001$. breathing). Sponsel $e t a l,{ }^{22}$ using the same BFS technique, found a $23 \%$ increase in Vleuco during the breathing mixture of $16 \%$ oxygen, $5 \%$ carbon dioxide, and $79 \%$ nitrogen, a mixture that is similar to that occurring during RB. Some of the differences between our study and those mentioned above could be due to the fact that a closed rebreathing system produces continuous alterations in concentrations of inhaled gas, whereas in the other study the concentrations of the gases used were kept constant throughout the experiment. The continuous alterations in exhaled gas produced in the present study showed a larger effect on Vleuco than the constant one. Moreover, this large increase in Vleuco is not surprising since RB produces a large drop to $7 \%$ in oxygen level and to $8 \%$ in carbon dioxide in exhaled air at the end of RB. Even at 2 minutes of RB, end tidal oxygen concentration was $5-9 \%$ and carbon dioxide was $6 \cdot 4-8 \cdot 6 \%$. The end tidal carbon dioxide concentration can be considered to be close to the concentration in arterial blood since the lungs and the reservoir bag constitute a closed system. ${ }^{23}$

The RB procedure has the inherent disadvantage that for a short period of time there is a decrease in inspired oxygen which could be harmful to the ischaemic retina. This hypoxia, however, is very short lived and if it results in the dislodging of an embolus, it would provide an obvious advantage outweighing transient hypoxia.

Complete vascular occlusion causes severe ischaemia accompanied by the release of chemical mediators such as adenosine which produces marked vessel dilatation. ${ }^{24-26}$ It is possible that under conditions of long standing complete retinal artery occlusion RB may not result in any further.dilatation. Thus, RB may be beneficial only if administered quickly.

A different situation in which RB may be more useful could be in cases of amaurosis fugax which is thought to be caused by partial occlusion, spasms of the ophthalmic artery or emboli of a vessel. RB, which within 2 minutes produced a significant increase in Vleuco, could help dislodge the emboli and reopen the partially occluded vessels.

The current study shows that 2 minutes of $\mathrm{RB}$ results in a significant increase in Vleuco in young normal subjects. The long term goal of our efforts is to determine the efficacy of RB in preventing permanent visual loss following amaurosis fugax and impending RAO. This condition usually occurs in older people with risk factors such as atherosclerosis, hypertension, and cardiovascular disorder. ${ }^{27}$ Hypercapnia and hypoxia produced by RB could produce some systemic risk. ${ }^{28}$ Further studies need to be carefully done in these types of patients to assess the overall clinical usefulness of RB. It has been reported, however, that either branch or complete RAO can occur in relatively young patients in the third or fourth decade although this is rare. ${ }^{10}{ }^{29-32}$ The RB may be applicable for the treatment in an acute stage of such a devastating disease only in those young patients who are proved not to have systemic cardiovascular problems. 
This work was supported by the Pennsylvania Lions Sight Conservation and Eye Research Foundation.

The authors thank Thomas J McLaughlin for technical assistance.

1 Ellis PP. Occlusion of the central retinal artery after retrobulbar corticosteroid injection. Am $\mathcal{F}$ Ophthalmol 1978; 85: $352-6$.

2 Whiteman DW, Rosen DA, Pinkerton RMH. Retinal and choroidal microvascular embolism after intranasal corticosteroid injection. Am $\mathcal{F}$ Ophthalmol 1980; 89: 851-3.

3 Tsacopoulos M, David NJ. The effect of arterial pCO on relative retinal blood flow in monkeys. Invest Ophthalmol Vis Sci 1973; 12: 335-47.

4 Spalter HF, TenEick RE, Nahas GG. Effect of hypercapnia on retinal vessel size at constant intracranial pressure. $\mathrm{Am}$ f Ophthalmol 1964; 57: 741-5.

5 Eperon $G$, Johnson M, David NJ. The effect of arterial $\mathrm{pO}_{2}$ on relative retinal blood flow in monkeys. Invest Ophthalmol Vis Sci 1975; 14: 342-52.

6 Nunn JF. Applied respiratory physiology. 2nd ed. London: Butterworths, 1977: 55-61.

7 Lum LC. Hyperventilation and anxiety state. $f$ Roy Soc Med 1981; 74: 1-4.

8 Magarian GJ. Hyperventilation syndromes: infrequently recognized common expressions of anxiety and stress. Medicine 1982; 61: 219-36.

9 Van den Hout MA, Boek C, Margo van der Molen G, Jansen A, Griez E. Rebreathing to cope with hyperventilation: experimental tests of the paper bag method. $\mathcal{f}$ Behav Med 1988; 11: 303-10.

10 Arruga J, Sanders MD. Ophthalmologic findings in 70 patients with evidence of retinal embolism. Ophthalmology 1982; 89: 1336-47.

11 Wise,$G N$, Dollery CT, Henkind P. The retinal circulation. 1 st ed. New York: Harper \& Row, 1971: 314

12 Riva CE, Petrig BL. Blue field entopic phenomenon and blood velocity in the retinal capillaries. $\mathcal{f}$ Opt Soc Am 1980; 70: 1234-8.

13 Lotfi K, Grunwald JE. The effect of caffeine on the human macular circulation. Invest Ophthalmol Vis Sci 1991: 3028-32.

14 Schmid-Schonbein GW, Usami S, Skalak R, Chein S. The interaction of leukocytes and erythrocytes in capillary and interaction of leukocytes and erythrocytes in capillary and

postcapillary vessels. Microvasc Res $1980 ; 19: 45-70$.
15 Friedman E, Smith TR, Kuwabara T. Retinal microcirculation in vivo. Invest Ophthalmol Vis $S c i$ 1964; 3: 217-26.

16 Murphy ME, Johnson PC. Possible contribution of basement membrane to the structural rigidity of blood capillaries. Microvasc Res 1975; 9: 242-5.

17 Schmid-Schonbein GW, Skalak R, Usami S, Chein S. Cell distribution in capillary networks. Microvasc Res 1980; 19: $18-44$.

18. Slonim NB, Hamilton LH. Chemical regulation of pulmonary ventilation. In: Respiratory physiology. 5th ed. St Louis: Mosby, 1987: 193-6.

19 Fallon TJ, Maxwell D, Kohner EM. Retinal vascular autoregulation in conditions of hyperoxia and hypoxia using the blue field entopic phenomenon. Ophthalmology 1985; 92: 701-5.

20 Hickam JB, Frayser R. Studies of the retinal circulation in man. Circulation 1966; 33: 302-16.

21 Pakola SJ, Grunwald JE. Effect of oxygen and carbon dioxide on human retinal circulation. Invest Ophthalmol Vis $S_{c i}$ 1993; 34: 2866-70

22 Sponsel WE, DePaul KL, Zetlan SR. Retinal hemodynamic effects of carbon dioxide, hyperoxia, and mild hypoxia. Invest Ophthalmol Vis Sci 1992; 33: 1864-9.

23 Forster RE, DuBois AB, Briscoe WA, Fisher AB. Blood oxygen, carbon dioxide, and $\mathrm{pH}$. In: Forster RE, DuBois $\mathrm{AB}$, Briscoe WA, Fisher AB, eds. The lung. Chicago: Year Book Medical Publishers, 1986: 223-47.

24 Phillis JW, Walter GA, O'Regan MH, Stair RE. Increases in cerebral cortical perfusate adenosine and inosine concentrations during hypoxia and ischemia. $\mathcal{f}$ Cereb Blood Flow Metab 1987; 7: 679-86.

25 Berne RM, Rubio R, Curnish RR. Release of adenosine from ischemic brain. Effect on cerebral vascular resistance and incorporation into cerebral adenine nucleotides. Circ Res 1974; 35: 262-71.

26 Forrester T, Harper AM, MacKenzie ET, Thomson EM Effect of adenosine triphosphate and some derivatives on cerebral blood flow and metabolism. $\mathfrak{f}$ Physiol (Lond) 1979; 296: 343-55.

27 Brown GC. Retinal arterial obstructive disease. In: Ryan SJ, ed. Retina. Vol 2. St Louis: Mosby, 1989: 403-19.

28 Callaham $M$. Hypoxic hazards of traditional paper bag rebreathing in hyperventilating patients. Ann Emerg Med 1989; 18: 622-8.

29 Lam BL, Siatkowski RM, Fox GM, Glaser JS. Visual loss in pseudotumor cerebri from branch retinal artery occlusion. Am $\mathcal{f}$ Ophthalmol 1992; 113: 334-6.

30 Hausmann N, Richard G. Effect of high dose steroid bolus on occlusion of ocular central artery. Angiographic study. on occlusion of ocular

31 Wenzler EM, Rademakers AJM, Boers GHJ, Cruysberg JRM, Webers CAB, Deutman AF. Hyperhomocysteinemia in retinal artery and retinal vein homocysteinemia in retinal artery and retin

32 Brown GC, Magargal LE, Shields JA, Goldberg RE, Walsh PN. Retinal arterial obstruction in children and young adults. Ophthalmology 1981; 88: 18-25. 